University of South Carolina

Scholar Commons

$5-2005$

\title{
Using Computer-mediated Communication to Establish Social and Supportive Environments in Teacher Education
}

Nike Arnold

Lara Ducate

University of South Carolina - Columbia, ducate@mailbox.sc.edu

Lara Lomicka

University of South Carolina - Columbia, lomicka@sc.edu

Gillian Lord

Follow this and additional works at: https://scholarcommons.sc.edu/ling_facpub

Part of the Linguistics Commons

\section{Publication Info}

Published in CALICO Journal, Volume 22, Issue 3, 2005, pages 537-566.

Arnold, N., Ducate, L., Lomicka, L., \& Lord, G. (2005). Using Computer-mediated Communication to Establish Social and Supportive Environments in Teacher Education. CALICO Journal, 22(3), 537-566. (C) 2005 CALICO Journal

This Article is brought to you by the Linguistics, Program of at Scholar Commons. It has been accepted for inclusion in Faculty Publications by an authorized administrator of Scholar Commons. For more information, please contact digres@mailbox.sc.edu. 


\title{
Using Computer-mediated Communication to Establish Social and Supportive Environments in Teacher Education
}

\author{
Nike ARnOLD* \\ University of Tennessee \\ LARa Ducate \\ LARA LOMICKA \\ University of South Carolina \\ GILLIAN LORD \\ University of Florida
}

\section{ABSTRACT}

This article examines social presence in virtual asynchronous learning communities among foreign language teachers. We present the findings of two studies investigating cross-institutional asynchronous forums created to engage participants in online dialogues regarding their foreign language teacher preparation experiences in and out of the classroom. Both studies took place during Fall 2003 and were conducted between first-time teacher/graduate students in four methodology courses at three large state universities. In the first study, students participated in weekly online exchanges in the form of dialogue journals for reflective teaching. In the second study, students were provided with specific topics to address using a discussion board, related both to theoretical language learning issues as well as pedagogical classroom-related concerns. The data analyzed here consist of the contributions and responses submitted by all participants on their respective online forums. We analyze these data qualitatively using Rourke, Anderson, Garrison, and Archer's (2001) framework in order to gain a better understanding of the element of social presence-specifically affective, interactive, and cohesive indicators as they occur during asynchronous online discussion. This study marks an important contribution to the literature as it examines how virtual discussion takes shape, how the notion of social presence is defined in these foreign language teacher communities, as well as the implications for language teacher education in computer-mediated communication.

\section{KEYWORDS}

Computer-mediated Communication (CMC), Virtual Learning Community (VLC), Social Environments, Social Presence, Foreign Language (FL) Teacher Education

*Authors are listed in alphabetical order and contributed equally to this article. 


\section{INTRODUCTION}

While most articles in this issue investigate the use of computer-mediated communication $(\mathrm{CMC})$ for foreign language learning, this paper focuses on the role of CMC in foreign language (FL) teacher education and on how to assist teachers in training programs to create and maintain professional learning communities. In recent years, $\mathrm{CMC}$ has been implemented more and more to promote the professional development of future and current FL teachers. One reason for this trend is the importance administrators place on the use of technology in today's classrooms. This development is reflected in the 2002 Program Standards for the Preparation of Foreign Language Teachers (American Council on the Teaching of Foreign Languages, 2002), where ACTFL emphasized the importance of providing future teachers with opportunities to experience computer-enhanced instruction in order to use new technologies for their own teaching. In addition, $\mathrm{CMC}$ has been implemented in teacher training to provide an interactive venue for reflection and critical thinking on the one hand and collegial support, advice, and mentoring on the other (Bonk, Hansen, Grabner-Hagen, Lazar, \& Mirabelli, 1996; Kamhi-Stein, 2000; Liou, 2001; Pawan, Paulus, Yalcin, \& Chang, 2003).

Using CMC to create a supportive and collegial environment for teachers as described above involves the creation of a community, which is the focus of this article. Lock (2002) defines a community not as

an entity or a product. Rather, it is a process, which is fluid in nature. A community evolves through nurturing conditions ... It is a supportive and empowering environment that accommodates and is responsive to the members' actions, interactions, and reactions. (p. 395)

While the present discussion of community specifically focuses on the creation of positive functional communities that can enable constructive interaction, reflection, and professional development, there is also dysfunctional behavior in cyberspace that serves to divide and exclude rather than foster community (Kollock \& Smith, 1999), such as swearing or rude language, which is often referred to as flaming (Abrams, 2003). While communities' behaviors are a worthy topic to investigate, we have chosen to focus our analysis on the discourse functions that may contribute to building constructive networks. Specifically, we explore how $\mathrm{CMC}$ can facilitate positive social interactions and the formation of communities for professional growth among FL teachers.

Since current views of learning and knowing emphasize social processes, communities play an important role in learning. Wenger (1998) states that "the learning that is most personally transformative turns out to be the learning that involves membership in ... communities of practice" (p. 6). Therefore, it is essential that the act of learning encompass actions, as well as interactions and reflections. Over time, collective learning creates a community of practice, whose foundation is a set of practices reflecting students' social relations as well as their shared pursuits (Wenger, 1998). In such communities of practice, "things have to be done, relationships worked out, processes invented, situations interpreted, artifacts pro- 
duced, conflicts resolved" (Wenger, 1998, p. 49). As we will argue in this article, $\mathrm{CMC}$ can be used as a social tool to establish a supportive community with unique practices.

\section{CMC as a Social Tool}

Based on early research studies, CMC has been considered too impersonal (Baron, 1984; Kiesler, Siegel, \& McGuire, 1984) for such communicative purposes because of its lack of paralinguistic cues. Since most CMC is purely text based, nonverbal behavior such as nodding, frowning or gesture articulation is not transmitted to interlocutors. Kiesler et al. (1984) have referred to this characteristic as the "dramaturgical weakness" of CMC (p. 1125). The belief that CMC is not suitable for bonding or community building is reflected in the following statement made by Baron (1984): "CMC - at least as currently used - is ill-suited for such 'social' uses of language" (p. 136). However, due to the results of more recent studies, other researchers have expressed differing views. The media-deterministic view of $\mathrm{CMC}$ has lost influence, and CMC is no longer viewed as "socially impaired" (Baym, 1995).

Indeed, the results of many studies support the notion of $\mathrm{CMC}$ as a socially rich environment. In their study with 72 school children, Michinov, Michinov, and Toczek-Capelle (2004) found that only 90 minutes were enough for a sense of belonging to develop in synchronous CMC groups. Simply placing individuals in a group assisted in creating a sense of community. Tidwell and Walther (2002) compared CMC with face-to-face communication and found more intimate exchanges (e.g., disclosures) in the CMC medium. They suggested that the participants hyperpersonalized their online interactions by including more self-disclosures and less diluting filler elements (e.g., nonpersonal statements or statements about third parties) in order to compensate for the reduced amount of communication channels available in CMC (Tidwell \& Walther, 2002). Other studies have also shown that $\mathrm{CMC}$ is not a depersonalized medium but rather an environment where learners can build a classroom community, reach out to others, and provide each other with support (Cole, McCarthy Raffier, Rogan, \& Schleicher, 1998; Haythornthwaite, Kazmer, Robins, \& Shoemaker, 2000; Kamhi-Stein, 2000; McDonald \& Gibson, 1998; McKenzie \& Murphy, 2000; Sengupta, 2001). These findings illustrate that while communities were formerly defined by proximity, communities in urban societies can also exist over distance (Wellman, 1979) not only with the help of cars and telephones but also CMC (Haythornthwaite et al., 2000).

Apart from the positive and negative views of CMC illustrated above, a more flexible perspective has emerged. Several researchers have cautioned that viewing CMC as having fixed social effects might not be appropriate (Baym, 1995; Hollingshead \& McGrath, 1995; Metz, 1996; Walther, 1996). Walther (1996) proposed that "maybe the medium has no consistent effect-or has no effect at all - and different conditions surrounding CMC use lead to ... contrasting results" (p. 4). Based on the same premise, Spears \& Lea (1994) developed the SIDE model (= social identity and deindividuation), which is grounded in several psy- 
chological theories and accounts for CMC's potential to enhance as well as hinder an online group's homogeneity, identity, and social processes. Similarly, Baym (1995) argued that complex interactions between the following five factors make $\mathrm{CMC}$ interactions unpredictable: (a) external context, (b) temporal structure of the group, (c) infrastructure of the computer system, (d) the purpose for which CMC is used, and (e) the characteristics of the group and its members. Hollingshead and McGrath (1995) proposed a similar model, which places input factors, operating conditions, process variables, and outcome variables in functional relation to each other. Again, complex interactions between these variables are believed to affect the speed and quality of performance in online forums and determine the processes by which participants carry out tasks.

\section{Virtual Learning Communities (VLCs)}

If one accepts that social interactions are possible in CMC environments, as the authors of this article do, it is necessary to address the question of why it is important to consider this aspect of online interactions rather than focusing solely on the cognitive growth that can occur in CMC discussions through the exchange of information. According to Luppicini's (2003) classification, there are two types of virtual learning communities (VLC) whose main functions are of a social nature: VLCs of socialization and VLCs of counseling and development. However, social exchanges can also play an important role in VLCs of knowledge building, inquiry, practice, and culture. Most important, social activity in online forums seems to influence cognitive processes. In one model, four out of the five layers needed for effective collaboration relate to the social aspect of interaction: (a) support from the instructor, (b) getting acquainted, (c) establishing communication, and (d) building trust (Hasler-Waters \& Napier, 2002). In addition, Tu \& Corry (2002) defined social interaction as a dimension of VLCs that is related to and enhances instruction, while other studies have also offered support for the importance of social activity during CMC (McPherson \& Nunes, 2004; Molinari, 2004).

The belief that the social aspect of CMC is a necessary component of VLCs is also reflected in the detailed framework for the educational use of computer conferencing developed by Garrison, Anderson, and Archer (2001). Their framework states that in a virtual environment, learning occurs through the interaction of three core elements: cognitive presence, teaching presence, and social presence. The key element to success is cognitive presence, the learners' ability to engage in critical thinking and construct meaning through interaction. However, cognitive presence cannot be sustained if the participants do not project themselves into the community as genuine people, which Garrison et al. (2001) refer to as social presence. Social presence makes group interactions engaging, which in turn instigates and sustains critical thinking. Consequently, social presence plays an important supporting role in CMC and is thus worthy of further study in VLCs.

In an additional study, Rourke et al. (2001) refined and expanded the concept of social presence and its indicators. According to this modified framework, social presence is divided into affective, interactive, and cohesive categories. It is 
through the use of the following functions that participants of an online discussion establish their social presence: expression of emotions, use of humor, and self-disclosure [affective]; continuing a thread, quoting from others' messages, referring explicitly to others' messages, asking questions, complimenting, and expressing appreciation or agreement [interactive]; vocatives, addresses or references to the group using inclusive pronouns, phatics, and salutations [cohesive]. The definitions for each indicator are summarized in Table 1.

Table 1

Framework Used to Establish Social Events in VLCs, Modified from Rourke et al.'s (2001) Framework of a Community of Inquiry.

\begin{tabular}{|c|c|c|c|}
\hline \multirow{6}{*}{ 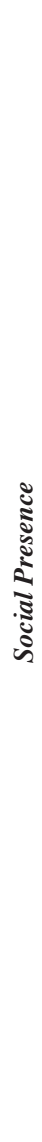 } & $\begin{array}{l}\text { AFFECTIVE RESPONSES } \\
\quad \text { Emotional Expression } \\
\text { = ability/ confidence to express } \\
\text { feelings related to educational } \\
\text { experience }\end{array}$ & $\begin{array}{l}\text { Humor } \\
\text { Teasing, } \\
\text { cajoling, irony, } \\
\text { understatements, } \\
\text { sarcasm } \\
\text { Self-Disclosure } \\
\text { Expressing } \\
\text { vulnerability } \\
\text { Self constructive } \\
\text { comments }\end{array}$ & $\begin{array}{l}\text { - Expression of emotions } \\
\text { - Conventional expressions } \\
\text { of emotion } \\
\text { - Unconventional } \\
\text { expressions of emotion } \\
\text { - Repetitious punctuation } \\
\text { - Conspicuous capitalization } \\
\text { - Emoticons }\end{array}$ \\
\hline & \multirow[t]{2}{*}{$\begin{array}{l}\text { INTERACTIVE RESPONSES } \\
\text { Open Communication } \\
=\text { reciprocal/respectful } \\
\text { exchanges }\end{array}$} & Mutual Awareness & $\begin{array}{l}\text { - Use of reply feature } \\
\text { - Quoting directly } \\
\text { - Directing a comment at an } \\
\text { individual }\end{array}$ \\
\hline & & $\begin{array}{l}\text { Recognition of } \\
\text { each other's } \\
\text { Contributions }\end{array}$ & $\begin{array}{l}\text { - Explicitly expressing } \\
\text { appreciation/agreement } \\
\text { - Complimenting others } \\
\text { - Encouraging others } \\
\text { - Asking questions } \\
\text { - Giving advice and seeking } \\
\text { opinion }\end{array}$ \\
\hline & \multirow{3}{*}{$\begin{array}{l}\text { COHESIVE RESPONSES } \\
\text { Group Cohesion } \\
\text { = activities that build/ sustain a } \\
\text { presence of group commitment; } \\
\text { focused collaborative } \\
\text { communication that builds } \\
\text { participation/ empathy }\end{array}$} & \multicolumn{2}{|c|}{$\begin{array}{l}\text { Vocatives - addressing or referring to participants by } \\
\text { name }\end{array}$} \\
\hline & & \multicolumn{2}{|c|}{$\begin{array}{l}\text { Inclusive pronouns - addressing group as we, our, } \\
\text { group, us, etc. }\end{array}$} \\
\hline & & \multicolumn{2}{|c|}{$\begin{array}{l}\text { Phatics, salutations - communication that serves a } \\
\text { purely social function: greetings, closures, etc. }\end{array}$} \\
\hline
\end{tabular}

In light of these works, it can be said that CMC often fosters social interaction, whether it is used for supportive or educational purposes. As Wellman \& Gulia (1999) state: "even when online groups are not designed to be supportive, they tend to be" (p. 173).

Foreign language teachers, especially those in the initial stages of professional 
development, can benefit from the aforementioned social advantages of VLCs. The support network established within the VLC can be a source of encouragement, corroboration, and cognitive growth both during the assigned discussions and during later semesters after teachers have established friendships through the VLCs. During the online discussions, the VLCs help students to establish and shape their identities as foreign language teachers as well as encourage higherlevel thinking. From the relationships forged online, teachers can continue to consult with each other about teaching, language questions, or issues that may arise during their future teaching careers. Nonnative speakers may, for example, use their native speaker contacts as a language or culture resource, or teachers could brainstorm various teaching lessons together.

In addition to these social benefits, after using $\mathrm{CMC}$ beginning teachers are more prepared to integrate it into their FL classes. Most important, CMC is a convenient tool to connect FL learners with the target culture and its people. In no other field has $\mathrm{CMC}$ had the potential to enhance instruction so dramatically since communication is at the core of both FL instruction and CMC. In addition, CMC provides an environment where communication in the FL tends to be more linguistically complex (e.g., Chun, 1994; Van Handle \& Corl, 1998), more evenly distributed among participants (e.g., Warschauer, 1996), and evoke less nervousness (e.g., Beauvois, 1998; Pérez, 2003). By first giving FL teachers the opportunity to learn with CMC themselves, they are more likely to use it for their own teaching (Lam, 2000), which means that more students will experience the many benefits of CMC.

\section{METHODOLOGY}

\section{Context}

The purpose of this paper is to provide an in-depth investigation and analysis of social construction in two different online communities and to examine the outcomes and implications of this construction. To our knowledge, there are no previous studies examining the role CMC plays in developing social presence across state and university boundaries to the end of fostering more effective FL teacher development communities. The goal of this article, then, is to examine how these communities develop in the context of teacher education courses, and how they can benefit the new teachers as they participate in these VLCs. The following section reports the findings of two studies, both of which sought to explore how online interlocutors relate to each other socially. Both studies discussed in this paper took place during the Fall 2003 academic semester and were conducted between first-time teacher/graduate students in four foreign-language teaching methodology courses at three large state universities in the southeastern United States. In the first study discussed here, students from the University \#1 (U1) and the University \#2 (U2) participated in weekly online exchanges in the form of dialogue journals for reflective teaching. Educators have long recognized the positive effects of self-reflection practices in teaching, and dialogue journals have been shown to be beneficial in opening channels of communication among learn- 
ers and providing supportive contexts for their development as teachers (Peyton, 1993). Student-teachers in this study participated in 10 discussion forums that were open ended in nature. In the second study, a different class of students (with a different professor) from U2 interacted with students from the University \#3 (U3). In this case, participants were provided with five specific topics to address using their discussion board, which were related to theoretical language learning issues as well as pedagogical classroom-related concerns.

\section{Analysis}

The data presented here are analyzed qualitatively, through an in-depth content analysis of all the electronic postings made by students over the course of the semester. Content analysis has been defined as "the systematic and replicable examination of symbols of communication, which have been assigned numeric values according to valid measurement rules using statistical methods, in order to describe communication, draw inferences about its meaning, or infer from the communication to its context, both of production and consumption" (Riffe, Lacy, \& Fico, 1998, p. 22). This specific method of analysis was employed as a means of generating hypotheses regarding the nature of social interaction in online communities. The data from both studies are analyzed using the social presence framework based on the work of Rourke et al. (2001), as discussed above. One of the major modifications to this framework was the elimination, within self-disclosure, of comments related to the presentation of details of life outside of class (or the discussion board environment), as the number of comments included within this indicator could potentially be overwhelming given the numerous discussions of teaching and other classroom-based experiences. While we do not discount the value of these interactions in the construction of a social environment, we found that the different nature of the tasks presented to our groups resulted in considerable variety in terms of content. Therefore, to err on the side of caution and to avoid overcoding comments that should not be construed as part of this framework, we eliminated this indicator. For affective interaction, then, we looked primarily at humor, sharing feelings, expressing vulnerability, and comments that can be construed as self-constructive. The latter indicator was one we added as a subcomponent to the vulnerability category due to the high volume of comments about how to improve teaching, although without necessarily expressing vulnerability.

To the interactive category established by Rourke et al., we added the indicators of 'giving advice/seeking opinion.' Again, these were dominant response types seen in our data that we classified as interactive since they, too, along with quoting, agreeing, and the other indicators in this category, serve to enhance the unity of the group and to mutually recognize each others' contributions. Finally, the indicators of cohesive interaction were those stipulated by Rourke et al., with no modifications. These categories were defined and explained in Table 1, above; examples from the current data set are provided in Table 2. 
Table 2

Categories, Indicators, and Examples of Social Presence (Adapted from Rourke et al.)

\begin{tabular}{|c|c|c|}
\hline Category & Indicator & Example \\
\hline \multicolumn{3}{|l|}{ AFFECTIVE } \\
\hline & Humor & Not a Webster's definition, but alas, I am not Webster! \\
\hline & Emotion & $\begin{array}{l}\ldots \text { I've been feeling more and more rushed and it } \\
\text { becomes a little stressful at times }\end{array}$ \\
\hline & $\begin{array}{l}\text { Expression of } \\
\text { Feeling }\end{array}$ & $\begin{array}{l}\text { My lesson plan is down the drain and the } 2 \text { hours that I } \\
\text { spent preparing my presentation are wasted!!! }\end{array}$ \\
\hline & CAPS/emphasis & COME ON!!!!!! \\
\hline & $\begin{array}{l}\text { Repetition of } \\
\text { Punctuation }\end{array}$ & $\begin{array}{l}\text { How can one learn without making errors??????? } \\
\text { Impossible! }\end{array}$ \\
\hline & Emoticons & :) \\
\hline & Vulnerability & I had one flop yesterday. \\
\hline & Self-Constructive & $\begin{array}{l}\text { But I'll definitely have to find a balance between the } \\
\text { four of them, and come up with the best mix each time. }\end{array}$ \\
\hline \multicolumn{3}{|c|}{ INTERACTIVE } \\
\hline & $\begin{array}{l}\text { Use of Reply } \\
\text { function }\end{array}$ & $\begin{array}{l}\text { In Reply to: Journal 5: Time is what I don't have! } \\
\text { posted by Cyrille on October 17, } 2003 \text { at 15:05:06: }\end{array}$ \\
\hline & Direct Quote & $\begin{array}{l}<<\text { They know I demand a lot and they are really } \\
\text { starting to respond the way I want them to. }>>\end{array}$ \\
\hline & $\begin{array}{l}\text { Directing a } \\
\text { Comment }\end{array}$ & $\begin{array}{l}\text { "Does your book include TPR exercises or you create } \\
\text { them for the class?" }\end{array}$ \\
\hline & Refer to Content & The issue of time also caught my eye and thoughts ... \\
\hline & Appreciation & Thanks for your informative post. \\
\hline & Complementing & ... but it sounds like you handled it well. \\
\hline & Encouraging & $\begin{array}{l}\text { Talk to your students and encourage them with verbal } \\
\text { praise. I know you can do it. The day that you told me } \\
\text { that I speak well, I felt really good. :-) }\end{array}$ \\
\hline & Asking Questions & $\begin{array}{l}\text { When you say you keep the } 5 \text { Cs present in your mind } \\
\text { is that something that's unique to you, or does the U1 } \\
\text { program actually encourage teachers to think about } \\
\text { the } 5 \mathrm{Cs} \text { ? }\end{array}$ \\
\hline & Advice/Opinion & I am open to suggestions. \\
\hline & Agreement & $\begin{array}{l}\text { I agree that pre-activities, as well as follow-up } \\
\text { activities, are quite important ... }\end{array}$ \\
\hline
\end{tabular}

COHESIVE

\begin{tabular}{ll} 
Vocatives (name) & David, \\
\hline Inclusive Pronouns & $\begin{array}{l}\text {... the TPR approach which we have discussed here; } \\
\text { our online reflective journal project }\end{array}$ \\
\hline Phatics/Salutations & Have a good weekend \\
\hline
\end{tabular}


Given the potential for personal interpretation of the data in qualitative analyses, it was necessary to establish uniform coding among all the authors. After reaching an interrater reliability level of .87 or better in each of the two studies, researchers coded the units of measure, which combined both thematic and syntactical units, and were defined as single ideas or thoughts with no predetermined length. We examined each unit for elements of social presence as established in the described framework in order to determine the frequency of these different elements in both studies. Finally, we calculated social presence density figures for each category and each indicator, as discussed in Rourke et al. in order to compare our two studies in spite of different numbers of participants, threads, and tasks. The social presence density is calculated by dividing the number of instances of an indicator by the total number of words, and multiplying by 1000 ; this calculation offers a more precise way of examining what percentage or portion of the overall contribution was coded as one of the social responses. The next sections provide details about the methodology, results, and discussion for each of the two studies as we closely examine the notion of social presence.

\section{Study 1 - Virtual Electronic Journaling (U1/U2)}

In the first study, six students, all FL teachers or teachers in training, ranging in age from 22 to 37 and representing various nationalities (American, French, Italian, and Spanish) participated in a semester-long discussion forum on reflective teaching. Two university graduate seminars - one at U1 and the other at U2were set up to incorporate an electronic discussion forum in FL methodology courses, focusing on discussion of theoretical issues, historical perspectives, and recent innovations in the field of teaching of foreign languages.

Students were required to post 10 journal entries detailing their teaching experiences on a discussion board (a tool provided by U1), to which all group members had access and could post and respond freely. At the beginning of the semester, students were provided with a calendar of assignments, indicating the due dates for journal entries, as well as some general recommendations about how to structure and format all entries. While we did not want to give the students specific topics or themes to address, we did want to encourage in-depth reflection of their teaching. Therefore, we provided students with some general questions to consider when writing their entries. Based on Richards and Lockhart's (1996) guidelines on reflective teaching, these questions asked students to consider certain themes as they composed their journals, such as the goals of each language lesson and whether they were met; the most and least successful elements of a given period; changes they could make in a specific lesson or to their overall FL teaching philosophy as a result of a classroom experience; and, finally, student reactions to a lesson. There was no requirement about responding to the postings of peers, although the students generally responded frequently to the comments made by their virtual and local classmates. 


\section{Study 2 - Virtual Guided Discussions (U2/U3)}

For this study, students in a FL methodology course at either U2 or U3 used the discussion board feature of Blackboard to participate in five discussions over the course of one semester. Twenty-three students participated in this study, including new teaching assistants/associates of French, German, and Spanish; native and nonnative speakers of English, and three undergraduate students. The students at U3 were not yet teaching, whereas all but one of the students at U2 were teaching first-semester German. They were divided heterogeneously into groups of four or five with representatives from each university as well as different genders, age groups, target languages, and nationalities.

Each discussion lasted four to five days and focused on a topic provided by the instructors, who did not participate in the discussions. Students were provided with a grading rubric that encouraged them to interact with their group members and actively contribute to the discussions. While the topics represented different tasks (e.g., information exchange and application, evaluation), all of them required participants to make a connection between the theories of FL teaching/learning covered in class and real-life experiences (e.g., their own learning or teaching). For the first discussion, students were asked to get to know each other and discuss the advantages and disadvantages of native and nonnative FL teachers. This topic differed from the others because it had an explicit social component and students were not expected to make reference to any theories or readings. The following topics were provided for discussions 2-5: (a) describe and explain a past learning experience in light of a learning theory, (b) discuss how you have experienced motivation and anxiety when learning a FL and what teachers can do to influence such emotions, (c) introduce and evaluate the textbook you are/will be using, and (d) discuss how to integrate culture into a language class. These topics were all chosen because of their relevance to and great importance in FL classrooms.

\section{RESULTS}

Given the inherently different nature of the tasks (unstructured versus structured) involved in these two studies, we present the individual findings for each separately. In the final section we discuss the relevance of each study to the other and the implications that can be drawn from them in combination.

\section{Study $1-U 1 / U 2$}

Transcripts of the discussions over the semester contained a total of 116 posts from the six students, including original posts, comments and subsequent replies, consisting of a total of 45,290 words. From the 116 posts, comments were coded as social events in the three aforementioned categories of affective, interactive, and cohesive. The reader is referred again to Tables 1 and 2 for details regarding the coding procedure and the specific indicators used, while Table 3 below provides specific data regarding the findings of this study. 
Table 3

Results of Social Density for Study 1 (U1/U2) by Journal Entry

\begin{tabular}{|c|c|c|c|c|c|c|c|c|c|c|c|}
\hline & Prel & 1 & 2 & 3 & 4 & 5 & 6 & 7 & 8 & 9 & Total \\
\hline $\begin{array}{l}\text { Number of } \\
\text { posts }\end{array}$ & 13 & 20 & 17 & 7 & 10 & 11 & 10 & 9 & 10 & 9 & 116 \\
\hline $\begin{array}{l}\text { Number of } \\
\text { words }\end{array}$ & 6327 & 4575 & 6035 & 3847 & 4212 & 3778 & 4027 & 4228 & 3918 & 4343 & 45290 \\
\hline \multicolumn{12}{|l|}{ AFFECTIVE } \\
\hline Humor & 0.63 & 0.00 & 0.50 & 0.00 & 0.47 & 0.27 & 0.74 & 0.00 & 1.02 & 0.46 & 0.42 \\
\hline \multicolumn{12}{|l|}{ Emotion } \\
\hline $\begin{array}{l}\text { Expression of } \\
\text { feeling }\end{array}$ & 0.32 & 1.09 & 1.16 & 0.52 & 0.95 & 0.79 & 1.99 & 0.71 & 1.02 & 0.69 & 0.90 \\
\hline $\begin{array}{l}\text { CAPS/ } \\
\text { emphasis }\end{array}$ & 2.05 & 1.31 & 2.32 & 0.78 & 1.66 & 0.53 & 0.99 & 1.18 & 2.04 & 0.00 & 1.37 \\
\hline $\begin{array}{l}\text { Repetition of } \\
\text { punctuation }\end{array}$ & 0.47 & 0.00 & 0.66 & 1.04 & 0.71 & 0.26 & 0.50 & 0.71 & 1.79 & 0.00 & 0.60 \\
\hline Emoticons & 0.00 & 1.31 & 0.50 & 1.04 & 0.24 & 0.53 & 0.29 & 0.00 & 0.51 & 0.00 & 0.42 \\
\hline \multicolumn{12}{|l|}{ Self-Disclosure } \\
\hline Vulnerability & 0.47 & 0.00 & 0.16 & 0.78 & 2.85 & 0.26 & 0.00 & 0.95 & 1.53 & 0.92 & 0.75 \\
\hline $\begin{array}{l}\text { Self- } \\
\text { constructive }\end{array}$ & 0.95 & 2.40 & 0.66 & 3.38 & 1.66 & 1.32 & 0.74 & 1.89 & 0.77 & 1.38 & 1.46 \\
\hline Total affective & 4.90 & 6.12 & 5.96 & 7.54 & 8.55 & 3.97 & 5.21 & 5.44 & 8.68 & 3.45 & 5.92 \\
\hline \multicolumn{12}{|l|}{ INTERACTIVE } \\
\hline \multicolumn{12}{|c|}{ Mutual Awareness } \\
\hline $\begin{array}{l}\text { Use of reply } \\
\text { function }\end{array}$ & 0.47 & 3.28 & 1.82 & 0.26 & 0.95 & 1.06 & 0.99 & 0.71 & 1.02 & 0.69 & 1.15 \\
\hline Direct Quote & 0.00 & 0.66 & 0.66 & 0.52 & 0.71 & 0.00 & 0.00 & 0.47 & 0.25 & 0.00 & 0.33 \\
\hline $\begin{array}{l}\text { Directing a } \\
\text { comment }\end{array}$ & 0.63 & 3.50 & 3.15 & 0.78 & 1.19 & 1.85 & 0.99 & 1.89 & 1.53 & 1.38 & 1.72 \\
\hline $\begin{array}{l}\text { Refer to } \\
\text { content }\end{array}$ & 0.16 & 2.40 & 2.49 & 0.00 & 0.71 & 1.85 & 1.24 & 0.71 & 0.25 & 1.15 & 1.13 \\
\hline \multicolumn{12}{|l|}{ Recognition } \\
\hline Appreciation & 0.16 & 0.23 & 1.16 & 0.00 & 0.24 & 0.53 & 0.29 & 0.00 & 0.25 & 0.23 & 0.33 \\
\hline Compliment. & 0.16 & 1.09 & 1.33 & 0.00 & 0.95 & 0.00 & 0.29 & 1.42 & 0.25 & 0.69 & 0.64 \\
\hline Encouraging & 0.00 & 0.66 & 0.50 & 0.00 & 0.00 & 0.53 & 0.50 & 0.00 & 0.77 & 0.00 & 0.29 \\
\hline $\begin{array}{l}\text { Asking } \\
\text { questions }\end{array}$ & 0.16 & 1.09 & 2.15 & 1.04 & 0.71 & 1.85 & 0.74 & 0.47 & 0.77 & 0.92 & 0.99 \\
\hline $\begin{array}{l}\text { Advice/ } \\
\text { opinion }\end{array}$ & 0.32 & 3.28 & 1.99 & 0.52 & 0.95 & 1.32 & 0.99 & 0.47 & 1.02 & 0.92 & 1.19 \\
\hline Agreement & 0.32 & 1.31 & 0.83 & 0.52 & 1.19 & 0.79 & 0.50 & 0.71 & 0.25 & 0.00 & 0.64 \\
\hline $\begin{array}{l}\text { Total } \\
\text { interactive }\end{array}$ & 2.37 & 17.49 & 16.07 & 3.64 & 7.60 & 9.79 & 6.46 & 6.86 & 6.38 & 5.99 & 8.41 \\
\hline \multicolumn{12}{|l|}{ COHESIVE } \\
\hline $\begin{array}{l}\text { Vocatives } \\
\text { (name) }\end{array}$ & 0.63 & 3.50 & 2.98 & 0.00 & 0.95 & 1.85 & 1.74 & 0.95 & 1.79 & 0.92 & 1.57 \\
\hline $\begin{array}{l}\text { Inclusive } \\
\text { pronouns }\end{array}$ & 0.63 & 0.00 & 0.17 & 0.78 & 0.47 & 0.53 & 0.50 & 0.24 & 0.25 & 0.69 & 0.42 \\
\hline $\begin{array}{l}\text { Phatics/ } \\
\text { salutations }\end{array}$ & 0.47 & 1.75 & 0.83 & 0.26 & 0.71 & 0.79 & 1.24 & 0.47 & 0.25 & 0.92 & 0.84 \\
\hline Total cohesive & 1.74 & 5.23 & 3.98 & 1.04 & 2.14 & 3.18 & 3.48 & 1.66 & 2.30 & 2.53 & 2.76 \\
\hline $\begin{array}{l}\text { Total social } \\
\text { events }\end{array}$ & 9.01 & 28.85 & 26.01 & 12.22 & 18.28 & 16.94 & 15.15 & 13.95 & 17.36 & 11.97 & 16.43 \\
\hline
\end{tabular}


The theme of each journal was, as mentioned previously, dependent upon the students' own experiences in their classrooms, so it is difficult to identify clear trends over the course of the semester and any social presence differences between journal entries must be viewed cautiously because we cannot account for the variations. Nonetheless, it is interesting to note that the initial preliminary journal entry, which asked students for reflection on their beliefs about language teaching and encouraged very little social interaction, generated a high degree of social density overall, which subsequently leveled out over the course of the semester. Similar patterns emerge, relatively speaking, for the affective, interactive, and cohesive events that make up this total. This trend is consistent with the supposition that students make an effort for the first few weeks to construct their social community, after which it is assumed to be in tact and self-sustaining (see Molinari, 2004).

Again, though, given that we cannot trace each journal week to a particular theme or topic, in our case it is more beneficial to examine overall totals rather than difference between journal entries or trends developing over time. The overall pattern we observe in the $\mathrm{U} 1 / \mathrm{U} 2$ results is that the greatest number of social events occurred in the interactive domain, with a social presence density rating of 8.41 (i.e., an average of 8.41 interactive events per 1,000 words), followed by the affective domain with a rating of 5.92. Finally, cohesive events made up the smallest percentage of the social occurrences, at 2.76 social presence density. Each of the three types of social events is discussed in more detail below.

Affective events are those that express humor, emotion, or self-disclosure. This category accounted for just over one-third of all social events. The most common expression in this category fell under the self-disclosure category, the one which we had coded as self-constructive comments (66 occurrences $=$ a density of 1.46). These comments included students' suggestions on their own performance or critiquing themselves for the benefit of the other students, so that they could learn from each other. For example, one student described a fairly successful class activity, but continued, "The next time I use this activity, however, I plan to include a better example at the top of the page and to explain more thoroughly aloud, to ensure student understanding of the task directions; at first, they were a bit confused about the specific instructions of the activity." Another student, when discussing an activity relating to French vocabulary for jobs and professions that was not a success in his class, reasoned, "Maybe I should have modeled more jobs and given them more vocabulary at the beginning of class. I will try that the next time." In these types of comments, students clearly, after reflecting on their teaching experiences, were critical of their own teaching or ideas. The reflective nature of the task, however, did prompt students to think about, modify, and change elements of their teaching that did not produce successful results. The willingness of students to frequently share these critical comments and thoughts in a public forum was surprising. Unlike traditional journal writing, students put forth their thoughts and experiences for their peers, teachers, and even supervisors to read at both $\mathrm{U} 1$ and $\mathrm{U} 2$. As a result, students responded with suggestions, 
helpful comments, and encouragement, all of which established a sense of unity in their virtual community.

Another popular form of expression fell under the emotion category, namely the use of capital letters for emphasis (62 occurrences $=$ a density of 1.37). For example, one student expressed both his frustration and sounded a plea for help as he closed his entry of Journal 7 by asking, or rather, "shouting:" "DOES ANYONE HAVE A GOOD WAY TO MAKE SURE THAT EVERYONE IS GETTING PERTINENT INFO OUT OF MY LESSON????” In addition to emphasis through capitalization, we also see in this posting an example of repeated punctuation; thus, both emotional indicators are accounted for by the same utterance. Humorous events were more common in the preliminary journal entries, when students were getting to know each other and taking initial steps in building community, but dwindled as the semester progressed and the conversations became more indepth and task focused. Overall, only 19 instances of humor were expressed (= density of .42). Emoticons were also somewhat popular (= density of .42), most likely as a simple way to convey emotion in the otherwise text-based discussions. Of these, the smiley-face ":)" emoticon was the most popular, although there was a variety of other emoticons. The use of emoticons seemed to occur in phases; if one student used an emoticon, another would follow suit. The same trend occurred at different points during the discussions. While these visual faces were no doubt used to make up for lack of visuals, gestures, and tone of voice, the students found other ways to connect socially and did not resort to emoticons on a regular basis. In fact, Rourke et al. suggested that because emoticons occurred so rarely in their work, other researchers may wish to exclude them from analyses. Through their use of comments of self-disclosure and their use of humor and emotions, the students' virtual interactions enhanced the emotional and affective sense of community and sense of belonging.

Interactive exchanges are those that build and sustain relationships, provide evidence that the others are contributing members of the group, and indicate some kind of interpersonal support. For example, indicators of interactive exchanges often show mutual awareness within the group or recognition of the contributions members make to the group dynamic as a whole. In this category, we coded a total of 378 units, just under half $(49.03 \%)$ of the overall total social events. The majority of these indicators fell within the recognition subcategory, although mutual awareness indicators were also common. Examples of mutual awareness include using the reply function (= density of 1.15), directly quoting someone's previous message (= density of .33$)$, directing a comment to one specific person (= density of 1.72 ), or directly referring to previous ideas (= density of 1.13 ). In other words, students showed an awareness of the on-going nature of the collaborative dialogue by responding to each other's comments rather than initiating new and unrelated threads. The comment below, taken from a response to a response to a student's Journal \#5, exemplifies this mutual awareness:

Hi Cyrille, Thanks for your posting. From what I've read about total physical response (TPR) it does involve whole body movement to respond to com- 
mands. We will be discussing this more in our class on Wednesday. The way my supervising teacher in high school has presented it to me is different from that ....

The discussion on TPR was interesting to follow in that it not only referenced previous ideas, but it also, through a series of exchanges between a pair of students, showed evidence of negotiation and understanding of a concept (TPR). Students were motivated to find out more about the topic and acquire knowledge before relaying the information back to peers on the discussion board. Interactions such as these again show the students' awareness of the constant construction of their online community and the importance of responding and interacting as a group.

The recognition portion of the interactive category involves comments of appreciation and encouragement, asking for advice, expressing agreement, or complimenting another student's ideas or message, all of which again serve to strengthen the interaction between members of the group as a whole. We found evidence of question asking (= density of .99), as well as asking for or offering advice (= density of 1.19); also present (= density of .64) was the act of complimenting peers when they discussed both their positive and negative teaching endeavors. For example, one student offered this support to another, who expressed doubt about the adequacy of his activities: "It sounds like your activities (although they may have been long) were rather successful ... . I also like the fact that you had them ask follow-up questions." Other comments focused on ideas for FL teaching strategies, such as "You really had a great idea about the beanie dog! I'll have to borrow that for one of my classes!", while others referred more to the journaling process itself: "Overall a very interesting and thought-provoking journal entry." These comments signal students' awareness of and respect for the other members of the VLC and indicate that they were able to combine their learning with social development and interaction.

Finally, we turn to the cohesive category of indicators, which includes any techniques that serve to "build and sustain a sense of group commitment" (Rourke et al.), such as using someone's name, referring to the group as "we" or "us," or salutations. While this kind of social interaction comprised the smallest percentage of the overall number of social events, it is nonetheless a crucial component of the development of social community. The most common cohesive technique was referring to someone directly by name; in fact, there were 71 instances coded, by far the most popular cohesive technique (= density of 1.57). Many students, in addition to using the reply feature and referring to explicit content from previous posts, also made mention of the person whose message they referred to ("I second Damiano! What a great idea!") or directed comments specifically at one person ("Thank you very much, Michael"), as well as signing messages with their own names. As time went on, and as students got to know each other better, they seemed to mention peers by name with consistency but less frequently. These additional signals of group cohesion are especially important when we recall that in most discussion board forum software programs, as previously mentioned, us- 
ers are automatically provided with the option of replying to and quoting previous posts, so these indicators "may be a superficial artifact of conferencing communication rather than a defining indicator of social presence," whereas using someone's name, for example, is "a more conscious and willful effort on the part of the student to interact with others" (Rourke et al.). Students also used phatic comments and greetings when initiating or closing their posts as a sign of social unity. For example, comments such as "Hi all!" or "Have a great weekend everyone!" served to unify the group in a purely social way, without making reference to any posts or specific ideas.

As has become clear through the discussion of the results of this study, the students involved in this unstructured online journal collaboration did in fact engage in the construction of a social community. In addition to sharing ideas about teaching and their experiences as new teachers, they built relationships with the other members of the group and sustained these relationships over virtually the entire length of the semester. This social connection was undoubtedly essential in students' ability to successfully reflect upon and critique their progress as developing language teachers.

\section{Study 2-U2/U3}

Unlike the first study, this virtual interaction incorporated five explicitly assigned topics for participants to discuss, resulting in 469 posts and 88,652 words (see Table 4). This format allows us to examine not only overall social presence in the community but also to trace the development of this community through time as the semester progressed. Our discussion focuses on both of these aspects of the VLC.

As illustrated in the data in Table 4, the total number of instances of social presence steadily increased over each discussion. Specifically, instances of interactive and cohesive utterances increased over the course of the semester: interactive by almost six instances per 1000 words (from density of 12.74 to 18.22) and cohesive by four instances (from density of 9.42 to 13.99). The affective utterances, on the other hand, peaked during the third discussion and then decreased during the fourth and fifth discussions. Affective examples were also the least represented over the five discussions, while interactive utterances were the most common followed by cohesive utterances.

The relatively low number of affective comments in these data could have been due to the types of questions students were discussing. The topics provided by the instructors did not encourage expressions of emotion, which did not necessarily provide opportunities for students to express vulnerability or give themselves self-constructive feedback. Since students from U3 were not teaching yet, students from U2 seldom spoke about their own teaching experiences or how they could improve or change their teaching. If students did speak about themselves, it was more often in the context of sharing past language-learning experiences rather than current teaching experiences. 
Table 4

Results of Social Density for Study 2 (U2/U3) by Discussion

\begin{tabular}{|c|c|c|c|c|c|c|}
\hline & Disc. 1 & Disc. 2 & Disc. 3 & Disc. 4 & Disc. 5 & Total \\
\hline Number of posts & 69 & 105 & 90 & 94 & 111 & 469 \\
\hline Number of words & 12948 & 17810 & 21149 & 17157 & 19588 & 88652 \\
\hline \multicolumn{7}{|l|}{ AFFECTIVE } \\
\hline Humor & 0.00 & 0.50 & 0.24 & 0.17 & 0.20 & 0.24 \\
\hline \multicolumn{7}{|l|}{ Emotion } \\
\hline Expression of Feeling & 0.39 & 0.50 & 0.05 & 0.35 & 0.00 & 0.24 \\
\hline CAPS/emphasis & 0.69 & 0.77 & 0.95 & 0.17 & 0.77 & 0.69 \\
\hline Repetition of Punctuation & 0.77 & 0.50 & 0.71 & 0.47 & 0.46 & 0.57 \\
\hline Emoticons & 0.39 & 0.22 & 0.66 & 0.47 & 0.20 & 0.42 \\
\hline \multicolumn{7}{|l|}{ Self-Disclosure } \\
\hline Vulnerability & 0.15 & 0.00 & 1.42 & 0.06 & 0.05 & 0.38 \\
\hline Self-Constructive & 0.15 & 0.17 & 0.52 & 0.06 & 0.00 & 0.19 \\
\hline Total affective & 2.55 & 2.81 & 4.54 & 1.75 & 1.68 & 2.73 \\
\hline \multicolumn{7}{|l|}{ INTERACTIVE } \\
\hline \multicolumn{7}{|l|}{ Mutual Awareness } \\
\hline Reply function & 3.40 & 3.65 & 2.75 & 3.50 & 3.88 & 3.42 \\
\hline Direct Quote & 0.23 & 0.00 & 0.19 & 0.06 & 0.15 & 0.12 \\
\hline Directing a Comment & 0.23 & 0.73 & 1.04 & 1.98 & 0.61 & 0.95 \\
\hline Refer to Content & 3.47 & 4.72 & 4.11 & 4.25 & 6.94 & 4.80 \\
\hline \multicolumn{7}{|l|}{ Recognition } \\
\hline Appreciation & 0.08 & 0.28 & 0.05 & 0.00 & 0.41 & 0.17 \\
\hline Complimenting & 0.62 & 0.73 & 0.19 & 0.00 & 0.41 & 0.37 \\
\hline Encouraging & 0.23 & 0.62 & 0.52 & 0.41 & 0.36 & 0.32 \\
\hline Asking Questions & 2.78 & 2.86 & 1.47 & 2.04 & 2.19 & 2.21 \\
\hline Advice/Opinion & 0.15 & 0.00 & 0.28 & 0.87 & 0.51 & 0.37 \\
\hline Agreement & 1.54 & 0.90 & 1.75 & 1.11 & 2.60 & 1.61 \\
\hline Total interactive & 12.74 & 14.49 & 12.34 & 14.22 & 18.22 & 14.46 \\
\hline \multicolumn{7}{|l|}{ COHESIVE } \\
\hline Vocatives (name) & 2.39 & 3.71 & 4.16 & 4.14 & 5.10 & 4.02 \\
\hline Inclusive Pronouns & 0.69 & 0.73 & 0.85 & 1.98 & 2.76 & 1.43 \\
\hline Phatics/Salutations & 6.33 & 4.21 & 4.21 & 6.76 & 6.13 & 5.44 \\
\hline Total cohesive & 9.42 & 8.65 & 9.22 & 12.88 & 13.99 & 10.90 \\
\hline Total social events & 24.71 & 25.94 & 26.10 & 28.85 & 33.74 & 28.09 \\
\hline
\end{tabular}

While there were few examples of affective utterances throughout the discussions (= density of 2.73 ), discussion three had the most examples of capitaliza- 
tion, repetition of punctuation, emoticons, and vulnerability, and self-constructive comments (= density of 4.54). This topic focused on the students' experiences with motivation and anxiety in their FL classrooms as well as how they think teachers can best deal with these issues. Since the question focused on the emotions of anxiety and motivation, it is possible that students felt more compelled to share their emotions in their postings as they related past experiences to the topic. In the following example, a student shares how she felt about learning French.

[French] was the only class that I was EXCITED about attending, and the only class for which I ENJOYED doing homework. ... I am an EXTREMELY anxious person by nature so it is impossible for me to not stress about doing well in French when it is something I want to be perfect. And I am one of those people who feels like they aren't competent in a subject unless they are perfect in it and know it inside and out.

The capitalization in this posting helped the writer to convey her motivation about learning French as well as her anxiety caused by her desire for perfection. Once the writer initiated sharing vulnerability, the other participants in the discussion felt comfortable sharing their own stories of anxiety, making this discussion especially rich in terms of affective utterances in comparison to the other four discussions.

Cohesive utterances, including vocatives, inclusive pronouns, phatics, and salutations, were the second most common across all discussions (= density of 10.90) and were five times more likely to occur than affective utterances. Both vocatives and inclusive pronouns increased from discussion to discussion with instances of vocatives more than doubling between discussion one and five, while instances of inclusive pronouns almost quadrupled. It is likely that as students felt more comfortable with each other and the format of the discussion itself, they began to feel a greater sense of community within their groups. This solidarity is exemplified by the fact that they addressed each other more often by name and referred to the group as "we" and "us." In the following example, the writer asks his group members a question about culture during the fifth discussion.

Question for everyone ... I know that we have already talked about different cultural activities that we can do in the classroom. However, I am still interested in discovering new and meaningful ways in which we as teachers can incorporate this element into our daily teaching. Do you have any ideas? Susan ... question ... have you ever done anything with food?

In this example, the writer used the pronouns we and $u s$ to identify himself first as part of the discussion group and then as a teacher, simultaneously illustrating his membership in two communities. The use of vocatives and inclusive pronouns served the purpose of making the participants feel that they belonged to the learning community within the electronic discussions as well as to the larger community of FL teachers. As the discussion continued, the participants increased 
their use of vocatives and inclusive pronouns, thus increasing the bonds within the VLC.

Other cohesive tools students used to construct their learning communities were phatics and salutations, which began with high numbers in the first discussion, decreased in the second and third discussion, and then increased again during the fourth and fifth discussions. The high number of phatics and salutations in the first discussion was undoubtedly due to the fact the students were interested in learning about their fellow group members because they had been directed to get to know each other and so included introductions along with their answers to the main question. In the last two discussions, as the students began to get to know each other better, they began including more social comments in their postings. One group, for example, began an entire discussion about what kind of music they listen to in a P.S. section of their postings.

Interactive responses are represented by instances of mutual awareness and recognitions of each other's contributions and were the most common examples of social presence in study 2 (= density of 14.46$)$. In the category of mutual awareness, the use of the reply feature and the references to previously discussed content were the most salient examples of interactive responses. However, as mentioned earlier, Rourke et al. cautioned that the use of the reply feature is possibly not a reliable indicator of social presence because it is often a built-in component of the software, which was the case for this study. Other aspects of mutual awareness, such as directing a comment at an individual or referring to previously mentioned topics, require more effort than clicking on a reply button before responding to someone. Therefore the examples where one student referred to the content of another posting are perhaps more reliable indicators of mutual awareness between postings. Nonetheless, following Rourke et al., we continue to consider all indicators mentioned in their rubric.

Between discussions one and six, the instances of referring to previous content increased, slightly decreased between discussions two and three, and then increased again from discussions three to six. This increase suggests that as students were becoming more familiar with each other, they were also linking the specific content of their postings more often to that of other postings, thus engaging in more interactive exchanges. The following comment about culture shock and teaching culture illustrates how the student made reference to previous comments and then added his own opinion and experience:

In response to the preceding comments, it strikes me that this is a very subjective subject area. Each of you has expressed an opinion based on experience or on information shared by others. I guess that makes sense due to the personal nature of motivation and also response to cultural change. Personally, I can recall experiencing culture shock when I studied in Mexico last summer. ... As far as teaching culture goes, ... what do you think?

Rather than just express his opinion, this student tried to incorporate his comments into what had already been said and then invites other students to share 
their views. The more students demonstrated their interest in and awareness of what other members of their group had to contribute, the more likely other students were to express their opinions on various topics.

Recognition is another aspect of interactive responses that builds social presence. Certain aspects of recognition, such as appreciation, complimenting, and encouragement, were not well represented in the discussions; however, asking questions and expressing agreement were not uncommon. Since these discussions consisted mostly of brainstorming ideas about various topics in FL pedagogy, most postings consisted of relaying opinions and experiences about a certain topic and then asking the other group members for their opinion. A student replying to a previous posting would often agree or disagree with the previous posting and then offer his/her opinion. The format of the discussion therefore lent itself to a high number of questions and agreeing, as exemplified in the following example:

What could we do to create a relaxed non-anxious atmosphere among students that are low motivated (not all of course) and are anxious because they have to pass the course and are surrounded by a lot of unknown classmates who can criticize and make fun of their errors? Do you have ideas of how to work in this kind of situation?

In response to your question, Irma, that's not an easy answer in my opinion. I think here in the Spanish section, we have a good thing splitting up the different experience levels.

In the first quote, the student posed a question based on her experience in the FL classroom and then in the posting that followed, a student offered her comments in reference to the question and then continued the discussion. Posing questions helps to keep the discussion moving while illustrating to the other members of the group that their opinion is important and welcome, thus contributing to the establishment of the learning community.

To conclude this section, then, it is again obvious that a social community was undoubtedly developed through these discussions over the course of the semester. Clearly, there are differences between the social communities developed here and in Study 1 above, but it is nonetheless important to recognize that social presence is evident in both forums. In the following discussion, we investigate the differences and similarities observed in the two studies, and discuss some potential implications for future VLCs.

\section{DISCUSSION}

It is evident from the above discussions that both studies encouraged the successful development of online VLCs and that participants in these research projects were able to construct and maintain a high degree of social presence through CMC over the course of the semester. Nonetheless, there are differences between the studies that merit further attention for the relation they may have with the nature of the task and the group dynamic. Table 5 provides the data on both stud- 
ies for side-by-side comparison, while Figure 1 provides a visual comparison of affective, interactive, and cohesive social events between the two study groups.

Table 5

Social Presence Findings for Both Studies Presented in Raw Numbers of Tokens and in Social Density Figures

\begin{tabular}{|c|c|c|c|c|}
\hline \multirow{4}{*}{$\begin{array}{l}\text { Number of posts } \\
\text { Number of words }\end{array}$} & \multicolumn{2}{|c|}{ Study 1} & \multicolumn{2}{|c|}{ Study 2} \\
\hline & \multicolumn{2}{|c|}{116 posts } & \multicolumn{2}{|c|}{469 posts } \\
\hline & \multicolumn{2}{|c|}{45290 words } & \multicolumn{2}{|c|}{88652 words } \\
\hline & $\begin{array}{l}\text { Number of } \\
\text { Occurrences }\end{array}$ & $\begin{array}{c}\text { Density } \\
\text { (per } 1000 \text { words) }\end{array}$ & $\begin{array}{l}\text { Number of } \\
\text { Occurrences }\end{array}$ & $\begin{array}{c}\text { Density } \\
\text { (per } 1000 \text { words) }\end{array}$ \\
\hline \multicolumn{5}{|l|}{ AFFECTIVE } \\
\hline Humor & 19 & 0.42 & 21 & 0.24 \\
\hline \multicolumn{5}{|l|}{ Emotion } \\
\hline Expression of feeling & 41 & 0.90 & 21 & 0.24 \\
\hline CAPS/emphasis & 62 & 1.37 & 61 & 0.69 \\
\hline Repetition of punctuation & 27 & 0.57 & 51 & 0.57 \\
\hline Emoticons & 19 & 0.42 & 37 & 0.42 \\
\hline \multicolumn{5}{|l|}{ Self-disclosure } \\
\hline Vulnerability & 34 & 0.75 & 34 & 0.38 \\
\hline Self-constructive & 66 & 1.46 & 17 & 0.19 \\
\hline Total affective events & 268 & 5.92 & 242 & 2.73 \\
\hline
\end{tabular}

INTERACTIVE

Mutual awareness

Use of reply function 52

1.17

303

3.42

Direct quote

15

0.33

0.12

Directing a comment

78

1.72

0.95

Refer to content

1.08

4.80

Recognition

Appreciation

49

84

Complementing

15

0.33

0.17

Encouraging

29

0.64

0.38

Asking questions

13

0.29

0.44

Advice/opinion

45

0.99

2.21

Agreement

53

1.17

0.37

Total interactive events

28

0.62

1.61

378

8.35

143

14.51

\section{COHESIVE}

\begin{tabular}{lrrrr} 
Vocatives (name) & 71 & 1.57 & 356 & 4.02 \\
Inclusive pronouns & 19 & 0.42 & 12 & 1.44 \\
Phatics/salutations & 35 & 0.84 & 482 & 5.44 \\
Total cohesive events & 125 & 2.83 & 965 & 10.88 \\
\hline Total social events & 771 & 17.02 & 2490 & 28.09 \\
\hline
\end{tabular}


Figure 1

Social Density Comparison Between Study 1 and Study 2.

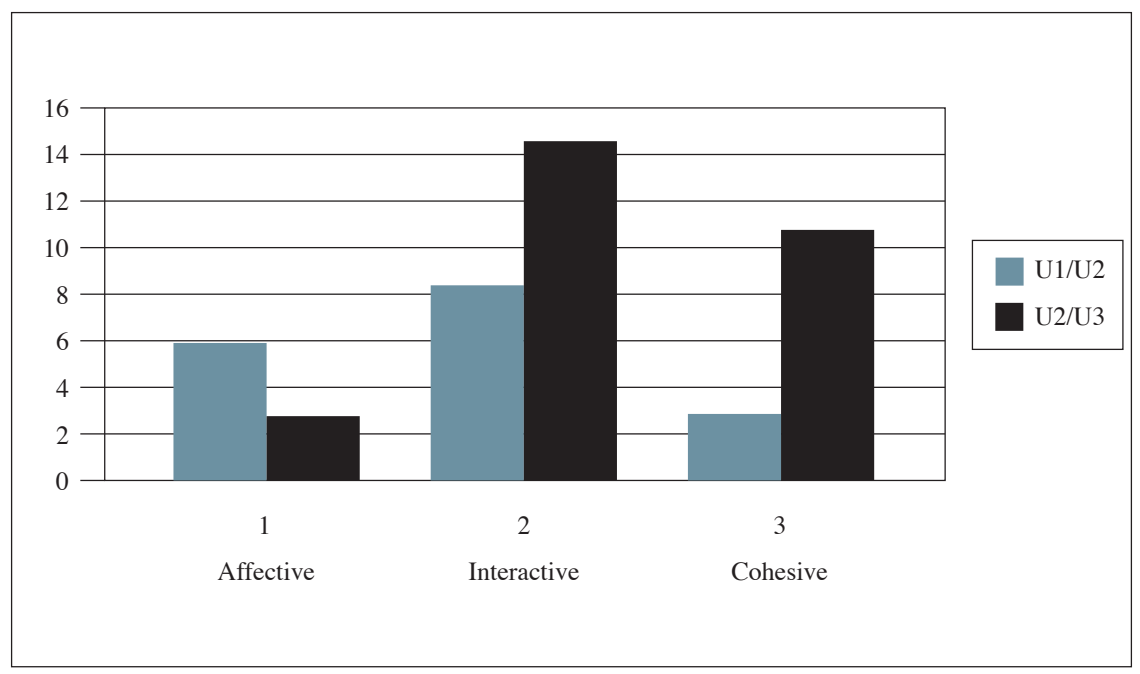

Clearly, in study 1 (U1/U2) the affective presence was considerably higher than in study 2 (U2/U3), whereas the latter dominated in interactive and cohesive measures.

We hypothesize that these differences in social presence density (which accounts and controls for difference in number of comments and number of words) are primarily the result of different task types, namely the structured (Study 2) versus unstructured (Study 1) assignments that participants engaged in, as well as different teaching circumstances for the different groups. As was suggested previously, the students in Study 1 were sharing their personal, and sometimes vulnerable, experiences as new teachers in the classroom, while most members of Study 2 were not teaching yet and therefore discussed more theoretical and abstract issues. In sharing such personal experiences, the students in Study 1 made more of an effort to connect on a personal-or affective-level with their new virtual peers. The humor and emotions they showed represent the way in which they dealt with sharing such personal experiences. On the other hand, the students in Study 2 did not feel quite the level of vulnerability that these students felt, and therefore we see markedly fewer instances of affective interaction.

Alternately, the participants in the U2/U3 study were responding to specific questions, so it is logical that their interactions include far greater percentages of agreements and responses, as the entire nature of their relationship depended on the sharing of ideas and agreeing and disagreeing. Because participants in the U1/U2 study were given a primary goal of discussing themselves and their own experiences in the classroom, the opportunities to agree or disagree, or even refer directly to others' comments, were more limited and less necessary. While the students in Study 2 had far greater social density presence in the interactive domain, showing the high degree to which they connected with each others' ideas on an 
individual as well as group level, students in Study 1 tended to direct their comments to all members of their group rather than reply to one particular member's comment or posting. The exception to this trend occurred when members chose to make very specific responses at the beginning or end of a message or to relate their own experiences to those of another group member, but this type of interaction was secondary to their primary goal of reflecting on their own growth as teachers.

Differences in the cohesive domain may also be explained by the nature of the task. The participants in Study 2 had far greater interaction overall and, as we have discussed, greater interactive social density; therefore, they had more opportunity to develop the cohesive aspects of their VLC. Since the group members were responding specifically to comments regarding specific ideas, they were more prone to use the names of specific group members. Even greetings and leave takings were more common, given the more conversational nature of their interactions, and the clear back-and-forth turn taking of their tasks. The students in Study 1 , while constructing their community, also had the option of viewing their online journal as just that - a journal, albeit one to share. Their task permitted an isolated entry dealing only with their own experiences, and in fact they received no particular instruction regarding the amount or degree of interaction that was expected from the other members of the group. These students, after the first few journals in which they made an effort to establish group cohesion, perhaps assumed the group dynamic had already taken shape. Therefore, the option of addressing other members and making inclusive gestures was not as necessary. This idea parallels findings of other VLC investigations, namely Molinari's (2004) recent work, in which she found that during the first third of the course, social activity dominated the messages but diminished over time. She hypothesized that the social activity at the beginning was aimed at building working relationships (as opposed to friendships) and that once these relationships were established, they could be assumed to be strong.

In Study 2, however, the social presence increased as the semester progressed. Rather than assuming that the group dynamic was formed during the first discussions, as the students may have done in Study 1, the participants in Study 2 continued to nurture their VLC. They also engaged in more social presence as they began to build more and more of a rapport with each other. These results from Study 2 contradict Molinari's (2004) findings and suggest that the participants did not just build working relationships throughout the discussions but also formed friendships, which can provide continuous support during their FL teaching careers. That finding may indicate that the social activity we observed was not just a means to an end (i.e., to make the discussions work) but instead served its own purpose of creating a community.

Of course, we cannot forget that individual differences in students, as well as their past computer experience, can also affect these data. For example, one student who is especially expressive may tend to use capital letters excessively, while another-more versed in CMC interaction-may employ more emoticons than other group members. In spite of these individual differences, though, the results 
taken from these two studies are still clear. Not only did both groups successfully construct the social presence necessary in any VLC, but, as we also saw, the type of task assigned to students can determine the nature of their social interaction.

Because the participants in this forum were FL teachers, we also looked at their use of different languages in their postings. Since both forums included teachers of different languages, the only common language assumed was English, which the instructors had established as the language for the discussions. Nonetheless, it is interesting to examine if and how foreign language words and expressions were used.

In study 1 (U1/U2), there were 22 instances of the members using FL words on the discussion board. Of these 22 instances, 20 were cases in which teachers explained what they had said or done in class, what they had written on the board, and so forth. Interestingly, in almost all of these situations, the student posting the message translated the foreign word or phrase into English for the other group members, except in the case of very obvious cognates, such as the French word optimiste. It seems that even though the members identified themselves to a certain degree with the language they were teaching, they were nonetheless very aware of the fact that the community to which they belonged was multilingual. In order to maintain this community, it was necessary to translate for the other members, which Wenger (1998) refers to as "practice." Communities are defined by their social context with their own assumptions, conventions, rules of thumb, and procedures, all of which provide structure and meaning to members. Although these "practices" may never be expressed in written form among members, "they are unmistakable signs of membership in communities of practice and are crucial to the success of their enterprises" (p. 47).

The two instances that were not classroom narration cases of FL use also seem to support the idea that the maintenance of community was a concern for the participants. One member, a teacher of French but a native speaker of Italian, ended one of his posts with buona fortuna after a discussion of some classroom problems and possible solutions. He did not translate this, but it was clearly a cohesive community-building device that served only a phatic purpose for the other members of the forum. Lastly, the other instance was by a native speaker of English who, in describing something he wrote in Spanish on the board in his class, unconsciously continued his posting in Spanish for a sentence or two until he realized that he had switched languages. He commented on the switch and then resumed in English. He did not translate this passage for his other group members, although he summarized what he had said in English right afterward. Perhaps for this nonnative speaker, his use of the target language was important for his membership in his other community, the community of Spanish language teachers. Yet when he realized that he was interacting in a community of FL teachers, he immediately reverted back to English to maintain the comprehension and reflection of that community.

In Study 2 (U2/U3), there were 34 examples of FL use. Most of the instances were greetings and goodbyes, and several were made by the same two participants. In addition to the greetings and goodbyes, there were two instances where 
students talked about food in the FL and five other examples where they used the FL when talking about the textbook or an example (explaining $t u$ vs. usted, for example), similar to the instances in study 1 . The remaining 27 examples were all greetings and goodbyes, such as chao, au revoir, à bientôt, wie geht's, que tengais un buen fin de semana, and espero que tengan un buen fin de semana. In only two cases was the phrase translated into English, which also occurred in study 1. However, there was one instance in which someone said goodbye in all three languages. This student was both being inclusive and noting everyone's membership in the FL teacher community. Although the exact meaning of some of these greetings may not be completely clear to someone who does not speak that language, the desired sentiment of the utterance espero que tengan un buen fin de semana, for example, is revealed in the context.

Among the U2 students, the two who wrote in the FL were native speakers, as was everyone else in the class, and among the U3 students, all who wrote in the FL were nonnative speakers of the language they were teaching. From these results, there does not seem to be a trend between native speakers or nonnative speakers utilizing the FL more often. One pattern we did notice was that when one student began using greetings or goodbyes in the target language, other group members would do the same. Therefore, in groups where no one started using the FL, there were fewer examples of its use. Rather than divide the community by using different FLs, this mirroring may have been used to build community.

From the above discussion, it is evident that study 1 and study 2 have differing results in regard to FL use in the discussion boards. While participants in study 1 seemed to consider FL use a disruption in the maintenance of the multilingual community, participants in study 2 employed the FL in greetings and goodbyes to confirm their membership in the discussion board community as well as the community of FL speakers and teachers. While it might be surprising at first that the two studies displayed very different practices concerning the use of FL in the discussion forums, this finding reinforces Wenger's (1998) belief that communities are defined by more than just their participants and institutional contexts. In fact, it is the interaction between their participants that makes communities unique, each with its own set of practices.

As evidenced in the above discussions of social presence and of the FL words used in the postings, the results of our studies hold implications not only for the development of online social communities in general but also for FL teacher education programs, as will be addressed in the concluding section.

\section{CONCLUSION}

As was discussed previously, educators have often been wary of using CMC tools because of the fear that such a depersonalized medium would effectively eliminate the possibility of developing social relationships or communities. Research has been conducted, however, documenting that CMC environments can in fact provide an environment that is suitable for building classroom communities and that promotes reaching out to and supporting others (Cole et al., 1998; Haythornthwaite et al., 2000; Kamhi-Stein, 2000; McKenzie \& Murphy, 2000; Sengupta, 
2001). The results of the studies described in this paper contribute to this literature, providing further confirmation that the novice FL teacher communities, which emerged through the use of $\mathrm{CMC}$, are indeed viable communities. In fact, the studies evidence multiple aspects of social presence, including affective, interactive, and cohesive interactions. Further, our findings support the research that has underscored the importance of social activity during CMC interactions (McPherson \& Nunes, 2004; Molinari, 2004) since the students involved at U1, $\mathrm{U} 2$, and U3 clearly relied on social activity to build their communities during electronic discussions.

In light of these findings, we conclude that CMC is a viable tool for FL teacher education that can and does include social elements; we also conclude that social interaction is a dimension of VLCs that is related to and enhances instruction, as proposed by Tu \& Corry (2002). FL teacher education programs can benefit immensely from continuing the types of projects described here. These kinds of projects allow novice teachers to connect with peers from a variety of language and educational backgrounds, opinions, classroom circumstances, and experiences, and to share and learn together. The social presence evident in these communities demonstrates that students did more than just carry out their assignments. They were also consciously aware of making important connections to other peers involved in the same goal of FL education and actively engaging in the process of developing their community, in spite of differences in space and time.

In addition, the majority of participants in both studies reported that they were encouraged to incorporate CMC and other similar tools into their own language classes after having participated in this project. The benefits of CMC in FL learning are widely documented in this special issue and elsewhere and were not the explicit focus of the projects described in this study. However, if such projects enable teachers in training to develop social presence in their VLCs that helps them to begin to form their identity as FL teachers and provide them with experience in using the technological tools that will benefit their teaching careers, we can only continue to encourage this kind of growth.

Also worth noting is the value of the interaction between teachers of different languages evident in the data. Since both groups consisted of students and beginning teachers of a variety of foreign languages, participants were encouraged to think on a more theoretical level and to discuss issues beyond the scope of their individual textbooks, syllabi, and classrooms. This aspect of the social interaction between students with diverse target languages and in various locations and FL programs is another feature of the type of community that may benefit future projects, especially since many FL education programs are confined to one language department and thus do not permit the students to learn from the experiences of teachers of other languages or from the challenges of teaching other languages.

When planning their own VLCs, FL teacher educators should also consider the differences reported here between these two studies. Unstructured reflective tasks seem to promote more affective interaction, while structured tasks seem to promote interactive and cohesive interactions. Also, we noted a difference in the nature of the interactions depending on whether the participants were currently 
teaching or not. Perhaps a combination of the two types of interaction would lead to even more successful and effective social community development, allowing learners to share their experiences and vulnerability while simultaneously encouraging the active exchange of opinions and beliefs. Doing so would also benefit new teachers by allowing them to investigate a greater variety of theoretical as well as practical issues in the course of their study, both of which most educators recognize as essential in teacher development.

Finally, as Muirhead (2000) has pointed out, further research is needed to explore the social dimension of CMC. Our sole focus, therefore, was to add to that body of research by exploring the development of social presence in online communities of FL teachers. It was not within the scope of our studies to consider cognitive development and interaction. Nonetheless, cognitive factors are certainly worthy of investigation and analysis. Data from future studies such as these can benefit teacher education by carefully examining virtual interaction in ways that lead to the development of new ideas and theories. Also relevant is the possible, and probable, connection between social presence and cognitive presence because the two are undoubtedly linked and may be even more closely tied together in online learning environments. We would encourage educators of foreign languages, and perhaps even those of other disciplines, to explore these additional paths for research as well as consider increased opportunities to create supportive networks outside of a single university environment for beginning teachers and graduate students.

\section{REFERENCES}

Abrams, Z. I. (2003). Flaming in CMC: Prometheus' fire or inferno's? CALICO Journal, 20 (2), 245-260.

American Council on the Teaching of Foreign Languages. (2002). ACTFL/NCATE Program standards for the preparation of foreign language teachers. Retrieved September 23, 2004, from http://www.actfl.org

Baron, N. S. (1984). Computer mediated communication as a force in language change. Visible Language, 18 (2), 118-141.

Baym, N. K. (1995). The emergence of community in computer-mediated communication. In S. G. Jones (Ed.), Cybersociety: Computer-mediated communication and community (pp. 138-163). Thousand Oaks, CA: Sage Publications.

Beauvois, M. H. (1998). E-talk: Computer-assisted classroom discussions-attitudes and motivation. In J. Swaffar, S. Romano, P. Markley, \& K. Arens (Eds.), Language learning online: Theory and practice in the ESL and L2 computer classroom (pp. 99-120). Austin, TX: Labyrinth Publications.

Bonk, C., Hansen, E., Grabner-Hagen, M., Lazar, S., \& Mirabelli, C. (1996). Time to 'connect': Synchronous and asynchronous case-based dialogue among pre-service teachers. In T. Liao (Ed.), Advanced educational technology: Research issues and future potential (pp. 289-314). Berlin: Springer Verlag. 
Chun, D. M. (1994). Using computer networking to facilitate the acquisition of interactive competence. System, 22 (1), 17-31.

Cole, R., McCarthy Raffier, L., Rogan, P., \& Schleicher, L. (1998). Interactive group journals: Learning as a dialogue among learners. TESOL Quarterly, 32 (3), 556568.

Garrison, R. D., Anderson, T., \& Archer, W. (2001). Critical thinking, cognitive presence and computer conferencing in distance education. American Journal of Distance Education, 15 (1), 7-23.

Hasler-Waters, L., \& Napier, W. (2002). Building and supporting student team collaboration in the virtual classroom. The Quarterly Review of Distance Education, 3 (3), 345-352.

Haythornthwaite, C., Kazmer, M. M., Robins, J., \& Shoemaker, S. (2000). Community development among distance learners: Temporal and technological dimensions. Journal of Computer Mediated Communication, 6 (1), 211-226.

Hollingshead, A. B., \& McGrath, J. B. (1995). Computer-assisted groups: A critical review of the empirical research. In R. Guzzo, E. Salas, \& I. L. Goldstein (Eds.), Team effectiveness and decision making in organizations (pp. 46-78). San Francisco: Jossey-Bass.

Kamhi-Stein, L. D. (2000). Integrating computer-mediated communication tools into the practicum. In K. E. Johnson (Ed.), Teacher education: Case studies in TESOL practice (pp. 119-136). Alexandria, VA: TESOL.

Kiesler, S., Siegel, J., \& McGuire, T. W. (1984). Social psychological aspects of computermediated communication. American Psychologist, 39 (10), 1123-1134.

Kollock, P., \& Smith, M. A. (1999). Communities in cyberspace. In M. A. Smith \& P. Kollock (Eds.), Communities in cyberspace (pp. 3-25). London, UK: Routledge.

Lam, Y. (2000). Technophilia vs. technophobia: A preliminary look at why second-language teachers do or do not use technology in their classrooms. Canadian Modern Language Review, 56 (3), 389-420.

Liou, H. (2001). Reflective practice in a pre-service teacher education process for high school English teachers in Taiwan. System, 29 (2), 197-208.

Lock, J. V. (2002). Laying the groundwork for the development of learning communities within online courses. The Quarterly Review of Distance Education, 3 (4), 395 408 .

Luppicini, R. (2003). Categories of virtual learning communities for educational design. The Quarterly Review of Distance Education, 4 (4), 409-416.

McDonald, J., \& Gibson, C. J. (1998). Interpersonal dynamics and group development in computer conferencing. The American Journal of Distance Education, 12 (1), $7-25$.

McKenzie, W., \& Murphy, D. (2000). "I hope this goes somewhere": Evaluation of an online discussion group. Australian Journal of Educational Technology, 16 (3), 239-257.

McPherson, M., \& Nunes, M. B. (2004). The failure of a virtual social space (VSS) designed to create a learning community: Lessons learned. British Journal of Educational Technology, 35 (3), 305-321. 
Metz, M. (1996). Balancing act: The struggle between orality and linearity in computermediated communication. The New Jersey Journal of Communication, 4 (1), 61-70.

Michinov, N., Michinov, E., \& Toczek-Capelle, M.-C. (2004). Social identity, group processes, and performance in synchronous computer-mediated communication. Group Dynamics: Theory, Research, and Practice, 8 (1), 27-39.

Molinari, D. L. (2004). The role of social comments in problem-solving groups in an online class. The American Journal of Distance Education, 18 (2), 89-101.

Muirhead, B. (2000). Interactivity in graduate distance education school. Educational Technology and Society, 3 (1), 93-96.

Pawan, F., Paulus, T. M., Yalcin, S., \& Chang, C.-F. (2003). Online learning: Patterns of engagement and interaction among in-service teachers. Language Learning \& Technology, 7 (3), 119-140. Retrieved February 25, 2005, from http://llt.msu. edu/vol7num3/pawan/default.html

Pérez, L. C. (2003). Foreign language productivity in synchronous versus asynchronous computer-mediated communication. CALICO Journal, 21 (1), 89-104.

Peyton, J. K. (1993). Dialogue journals: Interactive writing to develop language and literacy. Retrieved February 25, 2005, from http://www.cal.org/resources/digest/ peyton01.html

Richards, J. C., \& Lockhart, C. (1996). Reflective teaching in second language classrooms. Cambridge: Cambridge University Press.

Riffe, D., Lacy, S., \& Fico, F. (1998). Analyzing media messages: Using quantitative content analysis in research. New Jersey: Lawrence Erlbaum Associates Publishers.

Rourke, L., Anderson, T., Garrison, R. D., \& Archer, W. (2001). Assessing social presence in asynchronous text-based computer conferencing. Journal of Distance Education, 14 (2). Retrieved February 25, 2005, from http://cade.athabascau. ca/vol14.2/rourke_et_al.html

Sengupta, S. (2001). Exchanging ideas with peers in network-based classrooms: An aid or a pain? Language Learning \& Technology, 5 (1), 103-134. Retrieved February 25, 2005, from http://lit.msu.edu/vol5num1/sengupta/default.html

Spears, R., \& Lea, M. (1994). Panacea or panopticon? The hidden power in computer-mediated communication. Communication Research, 21 (4), 427-459.

Tidwell, L. C., \& Walther, J. B. (2002). Computer-mediated communication effects on disclosure, impressions, and interpersonal evaluations: Getting to know one another a bit at a time. Human Communication Research, 28 (3), 317-348.

Tu, C.-H., \& Corry, M. (2002). eLearning communities. The Quarterly Review of Distance Education, 3 (2), 207-218.

Van Handle, D. C., \& Corl, K. A. (1998). Extending the dialogue: Using electronic mail and the internet to promote conversation and writing in intermediate level German language courses. CALICO Journal, 15 (1-3), 129-143.

Walther, J. B. (1996). Computer-mediated communication: Impersonal, interpersonal, and hyperpersonal interaction. Communication Research, 23 (1), 3-43.

Warschauer, M. (1996). Comparing face-to-face and electronic discussion in the second language classroom. CALICO Journal, 13 (2), 7-26. 
Wellman, B. (1979). The community question: The intimate networks of East Yonkers. The American Journal of Sociology, 84 (5), 1201-1231.

Wellman, B., \& Gulia, M. (1999). Virtual communities as communities: Net surfers don't ride along. In M. A. Smith \& P. Kollock (Eds.), Communities in cyberspace (pp. 167-195). London: Routledge.

Wenger, E. (1998). Communities of practice: Learning, meaning, and identity. Cambridge, UK: Cambridge University Press.

\section{AUTHORS' BIODATA}

Nike Arnold is Assistant Professor of German at the University of Tennessee and directs the lower division German program. Her research focuses on individual learner differences, computer-mediated communication, and teacher training.

Lara Ducate is a Visiting Assistant Professor of German at the University of South Carolina and basic courses director of the lower division German program. Her research interests focus on teacher training, web logs, computer-mediated communication, and sociocultural theory.

Lara Lomicka is Assistant Professor of French at the University of South Carolina. Her research interests include telecollaborative environments, online learning, web logs, and teacher education. She has published several articles on technology as well as an edited volume entitled Teaching with Technology.

Gillian Lord is Assistant Professor of Spanish and Linguistics at the University of Florida, where she also directs the Intermediate Spanish program. Her interests include technology in language teaching, teacher training, and second language acquisition. She has published articles relating to collaborative learning and technology as well as other aspects of language acquisition.

\section{AUTHORS' ADDRESSES}

Nike Arnold

University of Tennessee

701 McClung Tower

Knoxville, TN 37996-0470

Phone: 865/974-0664

Fax: $\quad$ 865/974-7096 fax

Email: mnarnold@utk.edu

Lara Ducate

University of South Carolina

Columbia, SC 29208

Phone: 803/777-2205

Fax: $\quad 803 / 777-0454$

Email: ducate@sc.edu 
Lara Lomicka

University of South Carolina

Columbia, SC 29208

Phone: 803/777-2672

Fax: $\quad 803 / 777-0454$

Email: lomicka@sc.edu

Gillian Lord

University of Florida

PO Box 117405

Gainesville, FL 32611

Phone: 352/392-2016

Fax: $\quad 352 / 392-5679$

Email: glord@ufl.edu 